\title{
Horizons of the word: Words and tools in perception and action
}

\section{Hayden Kee ${ }^{1}$}

\author{
C) Springer Nature B.V. 2020
}

\begin{abstract}
In this paper I develop a novel account of the phenomenality of language by focusing on characteristics of perceived speech. I explore the extent to which the spoken word can be said to have a horizonal structure similar to that of spatiotemporal objects: our perception of each is informed by habitual associations and expectations formed through past experiences of the object or word and other associated objects and experiences. Specifically, the horizonal structure of speech in use can fruitfully be compared to that of a tool in use. The comparison suggests an account of our linguistic faculty as continuous with more foundational faculties of perception and action. I provide empirical corroboration of this account by drawing on recent neuroimaging studies of the multimodal, sensorimotor bases of speech comprehension. I then discuss how such an understanding of our linguistic ability helps advocates of embodied, nonrepresentationalist accounts of cognition respond to a common objection. Critics grant that embodied approaches may be adequate to account for lower-level, online modes of cognition, such as perception and action, which directly engage their object. But they question whether such approaches can "scale up" to higher modes of cognition, such as imagination, memory, thought, and language, which can entertain absent, non-existent, or abstract objects. By providing a plausible account of the continuity of lower cognition and language-involving cognition, my approach responds to this objection, at least where language is concerned.
\end{abstract}

Keywords Horizons · Phenomenology of language $\cdot 4$ e cognitive science $\cdot$ Scaling-up problem $\cdot$ Affordances

A name is a certain kind of tool meant for teaching and for the disentangling of being. - Plato ${ }^{1}$

${ }^{1}$ Cratylus, 388c.

Hayden Kee

hkee@fordham.edu

1 Fordham University, 441 E Fordham Rd. Bronx, New York City, NY 10458, USA 
[Speech] tears out or tears apart meanings in the undivided whole of the nameable, as our gestures do in that of the perceptible. - Merleau-Ponty ${ }^{2}$

\section{Introduction}

There is a longstanding philosophical tradition of comparing language as a whole, or specific words, to tools. The analogy dates back at least to Plato's "Cratylus." It was popularized in more recent times by Wittgenstein in his later work, while around the same time, across the Channel, Merleau-Ponty also toyed with the analogy throughout his writings. ${ }^{3}$ By and large, however, such discussions remain metaphorical. They are analogies meant to offer us some heuristically convenient way of thinking about this or that feature of language rather than attempts to literally tell us something about how language works or how we operate with it. This, at any rate, seems the only plausible way to read Socrates' cryptic - and profound - remark in the "Cratylus" that "a name is a certain kind of tool meant for teaching and for the disentangling of being" (388b-c), functionally analogous to the weaver's shuttle which separates warp and woof.

In this paper, I explore the extent to which such talk is not merely metaphorical. The word, I will argue, really does share a number of defining characteristics with extended, spatiotemporal objects more generally, an affinity best brought to light through comparison with tools in particular. I make this case by drawing attention to a feature of language too often neglected in most work in linguistics and philosophy of language: like a hand tool, language, preeminently as a spoken phenomenon, has its own materiality, that of sound, and is a perceived "thing," too, just like a tool. I elaborate these commonalities by clarifying the horizonal character of both tools and words as they are perceptually experienced. As a first approximation, the horizons of an object, tool, or (as I shall argue) a word are the networks of typical habitual associations that inform our perception of and interaction with that object, tool, or word and prefigure further continuations of experience with it. Though the origin of this notion can be traced to William James' discussion of the "fringe of consciousness" in his Principles of Psychology (James 1890), the concept was most rigorously developed in the phenomenological tradition, the work of Husserl in particular. ${ }^{4}$ However, as the current article is meant for a general audience, not just specialists in phenomenology, I will attempt to develop the notion without presupposing a specifically phenomenological conceptual framework or terminology beyond what I develop within this paper. Further, I will attempt to show how the first-personal, experiential phenomenon of the horizons of words and perceived things finds its correlate in neuroscientific evidence of how we perceive and understand objects and language respectively.

This attempt at understanding the similarities, analogies, and continuities between the horizonal structure of experiencing objects and words is of interest in its own right as a contribution to purely descriptive phenomenology. Further, however, there are many insights for philosophy of mind and language as well as for the cognitive sciences

\footnotetext{
2 Signes 24/17.

${ }^{3}$ See Merleau-Ponty 2012, 148, 180, 186, 192, 425; 1973, 52, 63, 86, 92, 95.

${ }^{4}$ See Geniusas 2012; Kwan 1990; Walton 1991, 2003.
} 
that follow from this way of understanding language. In this paper I pursue one. If, as I argue, perceiving and operating with words is in important respects comparable to perceiving and operating with tools, I will have established an important continuity between "lower-level" cognitive achievements of action and perception, and the supposedly "higher-level" achievements of our linguistic faculty. In doing so, I will have provided a means for advocates of representation-free and embodied approaches in the cognitive sciences to respond to a common critique of their research program. Skeptics about the scope of embodied cognition object that the accounts of representation-free perception and action provided by embodied approaches cannot "scale up" to deal with higher modes of cognition, such as imagination, memory, language, and long-term planning. In the final section of this paper, I will discuss how thinking of using words as continuous with using tools helps respond to this objection, and examine how my approach fares alongside other responses currently on the table.

I begin by describing the horizonal experience of perceptual things, a manual artifact in particular (Section 2). On the basis of this phenomenology of perceiving and operating with the artifact, I explore the extent to which the structures of perceiving and operating with language in speech can be understood with the same conceptual and phenomenological resources (Section 3). I explain how the comparison allows us to see that certain characteristics supposedly unique to language - such as grammaticality, reference to states of affairs remote in time and space, and diacritical signification - have more rudimentary precedents in our experience of spatiotemporal objects (Section 4). Having established the similarities between artifacts and words in these respects, I then discuss the neural correlates of word processing, showing how these reveal a considerable overlap in the underlying cognitive faculties that underwrite perceiving and operating with material objects (Section 5). Finally, I explain how exploring these similarities between words and artifacts helps proponents of embodied and representation-free approaches to cognition respond to the scaling-up problem (Section 6).

\section{Horizons of the tool}

In this section, I will discuss the horizons of a handheld artifact that we perceive and interact with in a customary way. My goal here is not to provide necessary and sufficient conditions for what counts as a tool or what constitutes the experience of interacting with a tool. I will be content to elaborate typical characteristics of a paradigmatic case of perceiving and employing a basic handheld tool, and to present the concept of the horizon in these terms. The analysis will then serve as a basis for comparing our ways of experiencing and operating with words. ${ }^{5}$

We can begin to grasp the notion of the horizon of an artifact by considering that no object is ever given in experience as radically and unprecedentedly new. We have a history of dealing with objects of different kinds that results in a set of loose presuppositions about them, as well as skills and habits of perception and action that inform our interactions with

\footnotetext{
5 This section draws on work by Husserl, Heidegger, Merleau-Ponty, Schutz, and Gurwitsch, and attempts to synthesize their ideas into a consistent presentation in an idiom that is recognizable as distinctively phenomenological while still being accessible to the non-specialist. If there is anything novel in this section, it is in that synthesis and presentation. The paper's original contributions will come in the following sections.
} 
familiar and novel objects alike. ${ }^{6}$ Even if I were to encounter some utterly bizarre alien artifact fallen from the heavens, I would still have some assumptions about how extended, spatiotemporal objects generally behave that will shape my engagement with this object. For example, I will expect it to have a backside that I can explore by turning it over or walking around it. If it is lying firmly on the ground compressing the grass beneath it rather than floating in the air, I will expect it to have a certain weight. For objects I am more familiar with, this network of prefigured expectations will be much denser and more determinate. If I pick up a new hockey stick at the local sports store, I will expect it to fit into my hands in a certain way and to have a certain weight and flexibility depending on the material it is made of. I will further expect that if I lace up my skates and hit the ice, I will be able to rely on this stick to perform a broad range of actions involved in playing a game of hockey, from raising it to signal to a teammate I'm free to receive a pass, to taking a slapshot, to crosschecking my opponent.

Perception of the object, we see, involves certain habitually structured expectations about the perceptual features of objects and the kinds of sensorimotor projects I can undertake with them. Of course, we do not need to be explicitly aware of any of these dimly prefigured aspects while perceiving the object. The lucidly simulated visual image or kinesthetic sensation of taking a slapshot need not play out before my mind's eye, as it were, when I see the hockey stick lying there on the rack in the store. However, the talk of a dim kind of "expectation" is warranted here precisely because I will be disappointed if the tool fails to satisfy such expectations. For example, if I take it off the rack and learn that it is a hollow display hockey stick, my reaction will be surprise, indicating that I had expected something else from this object. Similarly, if the first time I attempt a slapshot with the stick, it snaps in half, my sensorimotor expectation will be disappointed. Since I am not explicitly aware of these expectations in my first visual experience of the stick, and yet they prove to be entailed in my experience when they are disappointed, we can say that these expectations are implicitly or virtually co-present in my experience of the hockey stick. The collection of such vaguely implied expectations we can refer to as the horizon of the perceived object.

We can distinguish further between the inner and outer horizons of the object. ${ }^{7}$ The inner horizon includes those further predications that we would make of the object taken for itself, decontextualized of whatever external relations to other objects and activities into which it may enter. On my initial, vague perception of the object, there are any number of properties and concealed aspects waiting there to be discovered that I have not yet brought to explicit attention: Though I have a global grasp of the shape of the hockey stick, I may not be aware that the shaft is a rectangular prism with slightly rounded edges. I may not be aware of the material the stick is made of, whether wood, aluminum, fiberglass, or graphite. And though I may have seen that there is some text written on the shaft, I may need to explicitly direct my attention to it and obtain optimal distance, angle, and lighting in order to read it. Such continuations of my exploration of the object are vaguely foreshadowed in my initial perception of it and constitute the object's inner horizons.

\footnotetext{
${ }^{6}$ Husserl refers to this as a "familiarity" (Bekanntheit or Vorbekanntheit) characterized by "typicality," where "types" for Husserl designate a sort of proto-conceptuality active on the level of perception, somewhat akin to Kant's notion of a schema. See Husserl 1973, §8, 22; Lohmar 2008.

${ }^{7}$ Cf. Husserl 1973, §22; 1959, §49.
} 
The outer horizon, by contrast, includes the relational properties of the object. Here we can distinguish further between actual and empty outer horizons. ${ }^{8}$ The actual outer horizon is made up of everything that is also given in the current background of perception, but that is not the current focus of attention. When my eyes focus on one particular hockey stick in the store, the surrounding sticks, the rack on which they stand, the rest of the store, its customers, and the audible hustle and bustle of background conversations make up the actual outer horizon of my experience of the stick. The empty outer horizon, by contrast, consists of potential continuations of experience that are currently given neither focally nor as the background of my actual perception, but that could be actualized in the continued course of perception. Much of the sports store does not even make it into my peripheral vision as I inspect the hockey stick. It makes up the empty horizon of my current visual perception, features that I can render actual by turning my head or moving my eyes. Beyond the confines of this particular store, there is the rest of the shopping center, which is situated in a particular neighbourhood, of a particular city, in this particular country, all of which I may explore by moving my body through space. All of this makes up the empty outer horizon of my current experience. If we zoom out far enough, the ultimate empty horizon of all experience is the world itself, the "horizon of all horizons," as Husserl puts it.

What I have just said suffices for a provisional description of what we might call the empty spatiotemporal outer horizon of experience. However, the outer horizon of the hockey stick does not merely prefigure further spatial regions that I may explore and observe. Much more than this, as an object of possible practical interaction, the hockey stick prefigures a range of uses to which it may be put, projects I can undertake with it. Paradigmatically, the stick refers me to the activity of playing hockey itself, and all the relations that the stick and I would enter into were I to use it to play hockey: the whole equipmental network of pucks, skates, helmets, pads, nets; the typical setting of subzero temperature and ice, whether in the arena or on the pond; the intersubjective contexts of fellow players, coaches, referees, and fans; and the activities of shooting, passing, stickhandling, and checking - all of this is outlined in the empty horizon. ${ }^{9}$ In fact, insofar as my primary orientation towards the hockey stick is towards an object for practical purposes rather than towards a mere extended spatiotemporal object, we could say that these features of the outer horizon are in some respects even more salient in my experience of the stick than the empty outer spatiotemporal horizon of the shopping mall. Even if I were to find myself on a desert island and a perfectly functional hockey stick happened to be awaiting me there as the only sign of human life, the stick would still contain its reference to an empty outer horizon or practical employment. In this sense, the reference to ice in the stick's empty practical outer horizon is even more pronounced than the reference to the tropical ocean behind me in the stick's empty spatiotemporal outer horizon. Whereas the order of the empty spatiotemporal outer horizon is determined by spatiotemporal proximity, relations in the empty practical outer horizon are structured by what one might call the proximity of relevance. ${ }^{10}$

\footnotetext{
${ }^{8}$ Cf. Husserl 1959, \$49.

${ }^{9}$ Heidegger (1962, $\left.\S 14-18\right)$ refers to these nexuses of tools and references as the equipmental and referential nexuses (Zeugzusammenhang and Verweisungszusammenhang).

${ }^{10}$ On relevance, cf. Gurwitsch 2010, 331ff.
} 
It is tempting to think of the empty spatiotemporal outer horizon as delineating a set of determinate, individuated states of affairs that simply aren't being actually experienced in the current moment of perception. Similarly, one might think of the continuations of experience that the hockey player can engage in with the stick - every possible game she could play in every possible world in full determinate detail - as what is "prefigured" in the outer practical horizon. The empty outer horizons, both the practical and the spatiotemporal, on such an understanding would consist of the infinite disjunction of all such possible continuations of experience departing from the present moment. ${ }^{11}$ In a sense, this is correct. Reflecting after the hockey game, a player might realize that the game could have unfolded in any number of other determinate ways. In a sense, then, these parallel possible worlds were all contained in the outer horizon of the stick she took into her hands at the beginning of the game. But this retrospective, reflective, and, as it were, objectivist way of construing the empty outer horizon is not faithful to the way possibility is experienced by the subject as prefigured in the stick prior to the game. In that moment, the empty outer horizon is delineated not in terms of specific, determinate continuations of experience, but as a general, indeterminate, open, and schematic style or structure of interacting with the stick. ${ }^{12}$ The stick does not initially and for the most part refer to this or that specific puck, teammate, and action, nor to all possible pucks, teammates, and actions, but to pucks, teammates, and actions in general and to an open, skillful manner of interacting with them using the stick. Such possibility is prefigured not as discrete and determinate, parallel possible states of affairs, but rather as a vague and flexible play-space of possibility, sketched out according to habitual ways of interacting corresponding to my ability to use the stick, which is itself an open, flexible, and indeterminate ability. ${ }^{13}$ Such indeterminacy, viewed phenomenologically, should be treated as a positive phenomenon, not merely as a lack of determinacy.

This bodily potential for activity is dimly, passively "awakened," or elicited, when I perceive the stick. We may speak here of the activation of weak "motor image" of the associated activity of using the stick upon mere visual perception of it. ${ }^{14}$ In experiments designed to elicit motor imagery without execution of the correlated action (Bergen 2012), subjects sometimes speak of a tingling kinaesthetic sensation in the muscles associated with executing the correlated action, or of a slight bodily frustration at not being able to perform the action. Even when I have only visually seen the stick, my

\footnotetext{
${ }^{11}$ Husserl gives this impression when he illustrates the empty outer horizon in terms of a system of interconnected streets $(1959, \S 49)$. This seems to suggest that the nexus of interrelations that make up the empty outer horizon is static and readymade. Indeed, one of Husserl's favorite illustrations for the protentional character of consciousness more generally is listening to a melody that I already know. I anticipate the notes to come in a very determinate way in such a case. Contrast the case where I am listening to a melody I do not know, and the kind of expectations about the continuation of the melody that I make under such circumstances. They are much more open, loosely outlined by my familiarity, be it naïve or cultured, with harmonic conventions generally, rather than specific expectations about the precise tone and duration of the next note as in the case where I already know the melody.

${ }^{12}$ Husserl sometimes speaks of a style or form of determinability that characterizes the empty horizon (e.g., $1973, \S 8 ; 1982, \S 44 ; 1977,45)$.

${ }^{13}$ For Husserl, Heidegger, and Merleau-Ponty, our primary way of experiencing ourselves as agents in the world is in terms of a bodily, practical "I can" rather than a Cartesian, reflective, cognitive "I think." See, e.g., Husserl 1989, 231ff.; Merleau-Ponty 2012, $100 \mathrm{ff}$.

${ }^{14}$ In referring to these sensorimotor images as "weak," I have in mind the sense of weak phantasy developed by Lohmar $(2008,2010)$.
} 
body already begins to tremble in vague anticipation of the kinds of activity I would habitually undertake with it. This anticipatory priming of our sensorimotor ability makes up part of the experienced horizon of seeing the hockey stick. Again, it should not be mistaken for an explicit visualization or motor simulation of a specific action, whether in imagination or memory, although this first vague awakening of the motor image may prompt me to pursue an explicit simulation of one or another action.

We have seen that with the introduction of the practical horizon, the artifact also opens a horizon of intersubjectivity. The practical endeavors I undertake with the stick involve others, both specific others and others in general in their more or less determinate social roles (referee, coach, teammate, opponent, etc.). Along with these, we may speak of memorial and affective horizons (or, perhaps better, memorial and affective dimensions of the empty horizon) that perceiving an artifact may prompt us to pursue. When I hold a hockey stick in my hand today, I feel a vague sense of nostalgia for my youth and a time when I used to play more regularly. If I choose to give myself over to this nostalgia, I may follow a series of memorial associations into winter afternoons of my childhood spent on the frozen pond across the street from the home where I grew up, and hot chocolate with marshmallows when I returned home after dusk. For my nephew, by contrast, grabbing a hockey stick, even if only a miniature on the living room floor, may evoke the thrill of cool air in his lungs and the excitement of this weekend's upcoming game. ${ }^{15}$

Thus far we have spoken primarily of the horizons of the object when we are perceiving it in what we might call a observer's attitude. When it comes to a competent or expert agent using a well-functioning tool in a habitual way, taking the participant's attitude, something different happens. When I am skating down the ice at full speed and stickhandling with the puck, the stick is no longer the primary focus of my attention at all. If I am a novice player, my attention might be primarily directed towards the puck I am controlling through the stick. If $\mathrm{I}$ am an expert player, my attention is directed towards the positions and trajectories of my teammates and opponents within the space of significance laid out by the rink: the various painted lines that indicate my position and nearby thresholds on the rink, and the opposition goal that is my ultimate goal. ${ }^{16}$ That is to say, my attention is entirely immersed in actualizing one of the outerhorizonal possibilities that was only emptily prefigured by the hockey stick when it was the object of perception from within the observer's attitude. Immersed as I am in actualizing an outer-horizonal possibility of the stick, the stick itself and its inner horizon vanish entirely from my focus as the means through which I attempt to realize this possibility - just as the proverbial fish in water is oblivious to its watery medium. The stick becomes incorporated into my bodily praxis to such an extent that I am no more explicitly aware of it than I am of my body itself, even though my body constitutes the necessary medium within and through which my activity plays out. It is only when the stick lets me down that it becomes the focus of attention for me and I begin exploring its internal horizon again. If it breaks under my slap shot, I may suddenly find myself gaping in astonishment at the broken stick in my hands. Or if I am

\footnotetext{
${ }_{15}$ Quepons $(2015,2016)$ has employed the notion of horizon to explore affective dimensions of experience.

${ }^{16}$ Cf. Merleau-Ponty's description of how the football player experiences the space in which the match unfolds $(1963,168$ f.).
} 
experiencing a poor spell of form I may wonder if the tool is to blame and I will inspect the grip and tape as I skate back to the bench. ${ }^{17}$

Summing up, we can say that the outer horizon of the tool implicitly prefigures the affective, intersubjective, perceptual, and practical-sensorimotor possibilities of continued experience with the tool. These will vary tremendously from individual to individual depending on the expertise and past experiences one has with the tool in question, and the role it plays symbolically in the broader horizons of meaningfulness that make up a life. From the observer's attitude, as I sit at my desk and gaze whimsically at the hockey stick in the corner of my office, these possibilities are outlined as a virtual, vague horizon that, if I give myself over to memory or imagination, I can make more specific in one way or another by explicitly (re)enacting it in memory or imagination. Or I can simply bathe in the faint glow of nostalgia that the stick radiates for me. We can think here of Proust's madeleine and the vast horizon of memory and fantasy it unfolds for his narrator. However, we can also engage the stick in the participant's attitude, gearing up and hitting the ice with it. In this case, we are actually immersed in realizing some possibility delineated by the object's empty practical outer horizon, and in doing so we lose sight of the very stick that enables these horizonal possibilities.

\section{Horizons of the word}

In this section, I will pursue the comparison of the word to the tool and ask to what extent we may also think of the perceived word as possessing horizons like those of the tool. ${ }^{18}$ Some limitations of the present inquiry should be noted at the outset. (1) I will focus on the spoken word to the neglect of written language. The extent to which the advent of writing changes our relation to all language, including spoken language, cannot be further pursued here. ${ }^{19}$ (2) Though I will not be discussing signed languages, I believe that everything I say here about the spoken word in the auditory modality should also apply to the signed word in the visual-gestural modality. (3) I will be focusing primarily on concrete content words, such as nouns, verbs, and adjectives that can be used to pick out objects, events, and properties in the spatiotemporal environment. This means I am setting aside for the time being (a) abstract content words that do not obviously have a spatiotemporal referent and (b) function words such as conjunctions and prepositions that don't obviously perform a referential role. I believe there are principled reasons for treating such concrete content words as foundational within an individual's vocabulary, and to treat abstract and function words as derivative

\footnotetext{
${ }^{17}$ Cf. Heidegger $(1962, \S 16)$ on tool breakdown.

18 To my knowledge, this is an original proposal in the history of phenomenology. Heidegger (1962) implicitly entertains it when he asks whether language has the same kind of being as the tool. And Alfred Schutz (1962) proposed a very similar idea when he described a common appresentational character as the general form of symbolic and significative relations. As my primary objective here is not historical-exegetical, I will not pursue these connections further, though they warrant an independent study.

${ }^{19}$ The most obvious reason for excluding writing from the initial consideration is that the spoken word can exist in the absence of a codified system of writing - it has for vast majority of human experience and continues to do so for many humans today - but not vice versa. Derrida (1981) and others have problematized the supposed priority of speech over writing, but it is beyond the scope of the current paper to consider these critiques.
} 
or auxiliary with respect to concrete content words. But the argument for this view cannot be made here. ${ }^{20}, 21$

Perhaps no word class provides a better illustration of the horizonality of the word than the proper name. Because of the intimate association between the name and the

${ }^{20}$ On the concrete, embodied origins of abstract terms, see Deutscher 2005; Irwin 2017; Lakoff and Johnson
1999. On the experiential origins of some foundational function words, see Husserl 1969, 1973 .
${ }^{21}$ One might further wonder why we should focus on words at all, rather than utterances. After all, it is
comparatively seldom that we encounter a word in isolation in day-to-day parlance. Further, even within
linguistics, the notion of a word is a fuzzy concept. In some languages it is not even clear how the linguist
should individuate words.

By a "word," I understand something very close to whatever the minimally meaningful unit of speech is that a naïve language user (i.e., one who speaks the language naturally but has no scientific or philosophical views about her language) would recognize as such. Many linguists take morphemes to be minimal units of meaning. But I do not think most naïve language users would recognize the "s" suffix in "sticks" as a commonsensically meaningful unit of language, while "stick" is certainly capable of meaning something to a competent English speaker, even when removed from a sentential context. Indeed, a rough and ready criterion for identifying the kind of paradigmatic content words I am interested in would be any utterance that when spoken as a standalone utterance can constitute a pragmatically meaningful contribution to discourse. This would include responses to questions (A: "What are you looking for?" B: "Stick."), effective imperatives ("Faster!" "Stop!"); single-word informative utterances ("Fire!" "Fore!"), and some interjections ("Okay," "Ew!" "Whoa!").

On this understanding of the word, some multi-word expressions - such as my example of "hockey stick," which I will use below - would count as a single word. In this respect, the notion is closer to the linguistic concept of a lexeme than it is to that of the word. Of course, it is largely a convention of writing that we treat "hockey stick" as two words instead of one. Why, after all, are "skateboard" and "football" treated as one word, while "hockey stick" is treated as two? German, which is more permissive of agglutination than English, even adds a third word to create the compound "Eishockeyschläger." Here we see a certain written language bias will inform what the naïve language user will recognize as a word, and my notion of the word becomes a technical term to the extent that it departs from the folk-linguistic counterpart on this point.

My reasons for focusing on words are the following: (1) Words are the counterparts of the perceived objects and tools that they designate. Focusing on them aids in exploring the analogy between the horizons of words and tools, and their interrelations. (2) As I've just illustrated (and as Heidegger (1962) also noted), in everyday pragmatic contexts we do in fact encounter individual words in isolation. (3) At the crucial early stage of word learning, when word horizons are first being formed, children communicate primarily in single-word (holophrastic) utterances (Tomasello 2003). (4) Though I will not explore the topic in this paper, inner speech may employ language in a much more fragmentary, paratactic, and even holophrastic way than is normal in spoken or written discourse. This is an important realization for cognitive phenomenology, and the general account of word horizons I elaborate here should be applicable to that discussion, while an analysis in terms of utterances might not. (Cf. Bottineau 2010, 281 f., on the use of the word “dog” in inner speech. Proust's discussions of the role words play in inner speech and reverie might also be of interest here.) (5) Finally, from a methodological perspective, a certain degree of decontextualization allows us to isolate horizonal characteristics of speech that perhaps cannot be recognized within the normal flow of conversation, even if they are still operative there. My approach here is analogous to how Heidegger (1962) alternates between examining tools in normal use and tools in breakdown situations. During normal use, certain structural features of normal use itself often elude our phenomenal view. They can be brought to light when normal use breaks down. However, we must be careful not to absolutize the experience we have of the decontextualized tool or word. It must be placed back into its natural context. Heidegger's strategy of alternating between analyses of normal and breakdown situations is loosely parallel to my own alternation between observer and participant perspectives in the previous section.

Even if this reasoning is cogent and sufficiently motivates the focus on words, it should be acknowledged that this focus entails a somewhat artificial abstraction. Further, it applies better to comparatively more analytic languages (like English or Mandarin) than it does to the more synthetic languages (like German or most languages indigenous to North America). In any case, much of what I will say here about the phenomenality and horizonality of the word should also apply, with slight modifications, to the utterance. It would be an interesting and perhaps useful task to produce a comprehensive phenomenological inventory of units of speech and their mereology. But the undertaking lies beyond the scope of the present inquiry. 
object it names, and because of the concretion and specificity of the referent, names are especially rich in associated content.

I am sitting at my desk reading. I hear my girlfriend's phone ring in the next room. She answers it, but I cannot hear what she says through the wall. Some excited rumbling follows, and a moment later, she is at the door to my office, phone in hand, beaming smile on her face: "It's Tim!" she announces joyfully. My little brother Tim has been traveling the world since finishing college, and I have not heard his voice in months. Upon hearing his name, his face flashes before my mind's eye, a dim glimpse of Tim that is virtually awakened alongside the actual visual scene of my office and girlfriend that I am perceiving. The image, which flashes and then fades, is not of this or that particular memory of my little brother. It does not possess all the detail of an actual perception, nor even of a deliberately, actively conjured memorial or imaginative image. It is rather a dim adumbration of certain typical characteristics: a sheepish smile, bright blue eyes, ruffled hair - the typified, slightly caricaturized features of his face, depicting him before my mind's eye as always a little younger than he in fact is. Anticipating speaking to him on the phone, my ears are primed for his voice, and I can hear his cheerful greeting already. Along with these flashes of visual and acoustic imagery, a warm emotion floods over my body, in part conveyed by my girlfriend's enthusiasm, in part conjured up by the name itself and the thought of my brother it awakens. My whole bodily posture and comportment change. A moment ago, I had been aloof and secluded in my reading, my attention lost in some abstraction. Now my bodily attitude is more open, outgoing and welcoming. It is as though I, body and mind, were preparing to greet my brother with my smile and embrace him with my arms. I almost expect him to walk through the door into my office in the flesh.

The name, we can say, summons the named into a sort of pseudo-presence. It does so through activating the horizonal associations that we attach to the name and, by extension, to the object named. Let us explore these horizons by comparison with the horizons of the tool which we have discussed in the previous section.

The first similarity to note is that speaking is a bodily activity in some respects similar to other bodily activities (Bottineau 2010). And the word is a perceived spatiotemporal unity in some respects similar to the tool and spatiotemporal objects more generally. By that I do not mean that the heard word is the thematic object of a thetic act of perception, the way a hammer is when we stare dumbly at it without employing it. I simply mean that in normal use the word is taken up into the global, unfolding flow of perception, action, or thought just as the tool is assumed into the flow of perception and action in its normal use. ${ }^{22}$ The fact that speech is, in this sense, perceived might seem too obvious to be worth explicitly stating. And yet, it has been constantly overlooked within both the dominant tradition of post-Fregean analytic philosophy of language and within the phenomenological tradition, for reasons that are, as we will see in a moment, quite understandable. The tendency has been to speak of concepts, sense, meaning, and reference, but to ignore the special achievement of the perceived word as the bearer or vehicle of these semantic and logical properties of the word. Words in their experienced material-acoustic reality, we might say, have been

\footnotetext{
22 The point can also be made in terms of a distinction between epistemic and non-epistemic perception. See Dretske 1969. For a more recent discussion in connection with Husserl's phenomenology, see Welton 1983, 244f., and Welton 2000, 178.
} 
treated as merely instrumental, as a means through which one arrives at "meaning." However, in treating words as mere means, the possibility has been overlooked that their medial-instrumental character might uniquely structure the semantic and conceptual possibilities that it enables and constrains. ${ }^{23}$

Prior to asking about the "meaning" of a word, then - a notoriously unclear question in any case, and one fraught with theoretical presuppositions - phenomenologists should begin by attending to how we experience the word. The first thing to note is the feature of the spoken or signed word that differentiates it most dramatically from the extended spatiotemporal object, namely, the unique temporality of the spoken word, what linguists call the "rapid fading" of the speech signal. No sooner is the word "Tim" spoken than it is gone. The extended spatiotemporal object, by contrast, abides in time and space. As we will see, this feature of spoken discourse is especially important for allowing the word to serve its purpose of effacing itself in order to direct us towards its outer horizon. Since it is immediately gone as soon as it is spoken, it is less common for our attention to be arrested by some intrinsic property of the word itself and for us to take an observer's attitude towards speech. Once his name has been spoken, my thoughts are not with "Tim," but with Tim. Of course, at times we do ask for a word to be repeated, or we focus on the prosody of speech. We may redirect our attention to phonetic features of a spoken word when we are struggling to individuate or identify it, as when speaking a foreign language. Nonetheless, it is perhaps only with the advent of written language that the word acquires a suitable embodiment for its inner horizon to be grasped and explored in greater detail through the observer's attitude.

Since the inner horizon of the word rapidly vanishes, the outer horizons are all the more salient in our perception of the word. Beginning with the actual outer horizon, we may distinguish various aspects. There is, first, what we might call (1) the actual lexical outer horizon: words tend to come in sentences. In the middle of hearing a sentence, I hold in working memory the preceding words and am primed to expect certain other words to follow based on what I have heard thus far. ${ }^{24}$ The surrounding context of speech makes up the actual lexical outer horizon of the perceived word. Further, there is (2) the actual spatiotemporal outer horizon, consisting of the environing context in which I find myself as I am listening to my interlocutor; (3) the actual practical outer horizon, consisting of whatever is practically salient in my or our current activity; and (4) the actual intersubjective outer horizon, consisting of my interlocutor(s). Finally, there is what we might call (5) the actual attentional outer horizon: While passively perceiving what someone else is saying to me, I may be partially or fully attentionally directed towards something else entirely. For simplicity's sake, however, for the balance of this paper I will focus on the paradigm case where I am paying full attention to the speech I am hearing and the conversation we are having.

Turning now to the empty outer horizons of the word, note first that the specific, concrete form that these will take on in any case is heavily constrained, specified, and informed by all of the relevant actual outer horizons just discussed. When my girlfriend

\footnotetext{
$\overline{23}$ Important exceptions include Bottineau 2010; Cowley 2014; Kiverstein and Rietveld 2018; GahrnAndersen 2019.

${ }^{24}$ The phenomenological counterpart terms to working memory and such primed anticipation are retention and protention (Husserl 1964). I leave open the question concerning at what point a word held in retention should be seen as passing from an actual to an empty outer horizon. It seems to me that the border between such horizons is gradual rather than abrupt.
} 
walks into the room with the phone in her hand and announces, "It's Tim!" I am primed for the scene in a very different way than I would be if she walked into the room with a banana in her hand and made the same announcement. This is not entirely different from how the actual external horizon of a perceived object, such as the hockey stick discussed above, will make different features of the empty external horizon salient depending on context and my current attitude. Compare the horizonal effect of perceiving a hockey stick in the corner of my office, versus one in a store, versus one in a display case in the Hockey Hall of Fame, versus one in the hands of an opponent when I am actually playing hockey.

This thorough context-dependency makes it difficult to say anything about the empty outer horizon of a word in general. We can gain some insight into a sort of general horizonal schema, however, by considering a case where a single word is perceived and understood outside of any actual lexical context and in a comparatively neutral and decontextualized spatiotemporal, practical, and intersubjective context. Experimental work on language processing, which I will discuss at greater length below, presents such a context. Focusing on single-word perception of a concrete term such as "hockey stick," then, we can distinguish again between (1) an empty lexical outer horizon, and what we might call (2) an empty referential outer horizon.

(1) The empty lexical outer horizon will consist of typically associated terms, determined, for example, by syntagmatic and paradigmatic relations or other factors of association. For example, the lexical horizon of the term "hockey stick" will include associated terms such as "puck," "net," "goal," and so on. Such associated terms are more or less proximate within the empty lexical outer horizon, while the language as a whole, or perhaps my idiolect, constitutes the empty lexical horizon in its entirety.

(2) The empty referential outer horizon will consist of an indeterminate style of relating to hockey sticks in general. The word "hockey stick," that is, will elicit a dim sensorimotor anticipation of hockey sticks in general, or perhaps of an exemplary hockey stick. Hearing the word "hockey stick" weakly elicits the perception of a hockey stick, along with the associated empty horizons of an actually perceived hockey stick (including puck, net, goal, and so on). This will also hold mediately for the associated words in the empty lexical horizon, which will implicitly elicit their respective referential horizons. It is important to understand that the empty referential horizon is intentionally directed to the object: it consists of implied intentional relations of the language user to the referent in question. It relates the subject to an object (or typified object, or objects of this kind in general) in its sense for the subject. The name "Tim" does not refer to some individuated spacetime object independently of what speakers do with it. Rather, it relates me to my brother as I habitually perceive, interact with, and emotionally relate to him. The referential horizon, that is, relates us to a typified person or object in the sense that she or it has for us. ${ }^{25}$

Figure 1 shows the typology of horizons of the perceived word that I have just outlined. Note that there will be a certain degree of mirroring between the two empty horizons of

\footnotetext{
${ }^{25}$ Bottineau (2010) puts much the same point in even more forceful terms: "Speaking does not refer to the world; it causes an experience that happens to coincide or not with the narrow situation or the larger reality such as it is enacted, and has to be mapped against the environmental medium, including the psychological environment" (277).
} 


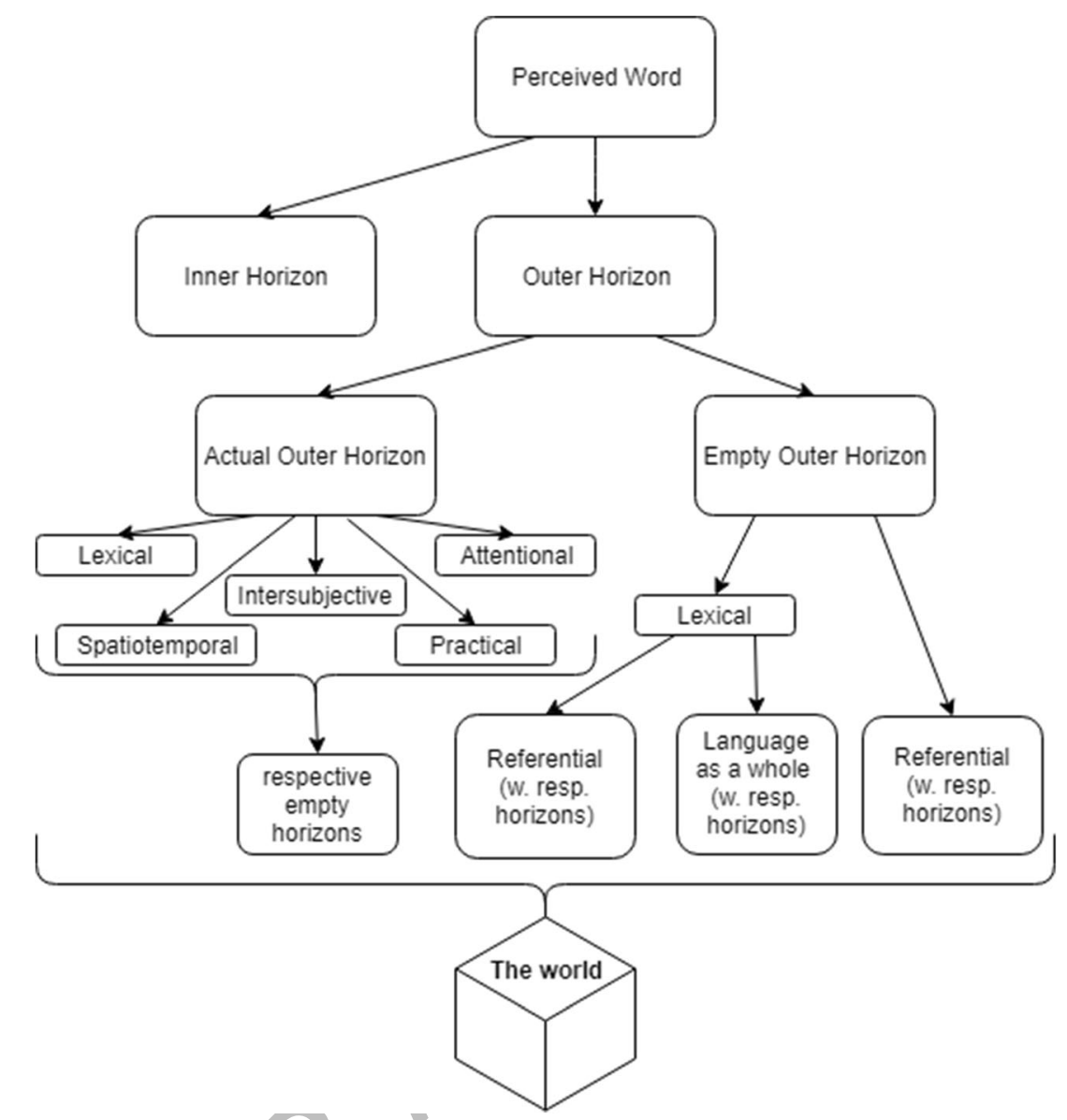

Fig. 1 Horizons of the word

the word, the lexical and referential. The terms associated in the lexical horizon of "hockey stick" will have within their respective referential horizons the things implicated within the associated horizons of the hockey stick itself which is the primary referent within the referential horizon of the term "hockey stick." To imagine the lexical and referential horizons in an horizonal space abstracted from any given moment of experience, then, we may picture two layers of horizonal associations, a dense one showing the referential relations between things, and a less dense one above it showing the horizonal relations between words. In addition to the lateral relations between things and words respectively, there will be myriad "vertical" associations running between things and words themselves. Though we can distinguish between two levels, however, the distinction is a relative one within the domain of perceptual experience itself, not between two different domains of our cognitive or experiential life.

In light of these considerations, we might also expand the discussion of the horizons of the tool, or the perceived object more generally, to include a lexical horizon. Because the associations we form between words and things run in both directions, perceiving an object will call to mind the name of that object, just as hearing the name will call to 
mind the thing named. And so, by horizonal implication, the hockey stick and its horizons of associated equipment are virtually awakened upon hearing the word "hockey stick" and, conversely, "hockey stick" and the associated hockey vocabulary are awakened upon seeing the hockey stick.

I do not claim that the typology presented in Fig. 1 is complete, nor that there may not be alternative possible typologies for fruitful phenomenological description of the horizonal space of perceived speech. Nonetheless, any alternative typology should account for the features accounted for in my typology. The empty outer horizon of all horizons is what phenomenologists call the world (cf. Walton 1997; Geniusas 2012, 195ff.).

This much we can say about the empty horizons in general, viewing them in a relatively decontextualized case. What, however, happens when words are put to work, as it were, in a more natural conversational context? As we saw above, when the hockey stick is being expertly put to work, the stick itself and its inner horizon vanish entirely from the explicit focus of the hockey player, whose attention is entirely devoted to actualizing a possibility previously prefigured in the empty outer horizon of the stick. Analogously, in flowing conversation, we are so fully absorbed in following what our interlocutor is saying and making our own contribution that we are not at all explicitly aware of the perceived word itself. The spoken word vanishes entirely from our focus in order to usher our attention along towards what we are discussing. And while the topic of discussion may be currently available to perception within the surrounding environment ("look at that hockey stick over there"), it needn't be. Indeed, we are not even constrained to speaking about real past, present, future, or even nomologically possible states of affairs ("Imagine Sidney Crosby is skating majestically in outer space, stickhandling through an intergalactic defense..."). ${ }^{26}$

Here we mark an important difference between the empty outer horizons of the word and those of the tool. The possibilities delineated in the empty outer horizons of the hockey stick are paradigmatically shaped by the kind of causal, spatiotemporal engagement into which the stick can enter. They depend on the sensorimotor cooperation of my body and the material interaction of the environment, real factors that are heavily constrained by causal laws. By contrast, the connection between the word and its empty outer horizon is entirely conventional and hence requires no such causal interaction between the spoken word and the horizons it delineates. The acquired associations that structure the empty outer horizon of the word, we might say, are established through arbitrary, conventional associations rather than through the material-causal interactions that primarily (though not exclusively) delineate the outer horizons of the tool. This is what makes the word such a powerful symbolic tool and scaffold for the imagination: the word can be de- and recontextualized with much greater ease than the actual tool. Consider three ways in which we could be presented with the state of affairs entertained above: "Sidney Crosby is skating majestically through outer space." (1) To actually perceive this state of affairs would require either a considerable transformation of the laws of nature as we know them or tremendous technological advances: under normal circumstances Sidney Crosby cannot skate in outer space. (2) Alternatively, I can

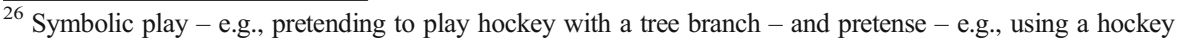
stick to pretend to play hockey in the absence of puck, ice, and opponents - are interesting intermediary cases between normal tool use and normal linguistic usage. Unsurprisingly, they appear to play an important role in language acquisition.
} 
visually simulate the image of Crosby skating in outer space. This is possible (I'm doing it right now) but requires a fair degree of concentration to entertain the image, burdening our cognitive resources and making it difficult to entertain further imagined variations and continuations of the state of affairs. By contrast, (3) with language I have a cognitively low-cost, empty way of entertaining the possibility of Sidney Crosby skating in outer space. Further, I can easily elaborate the state of affairs by playing with words, adding further whimsical variations and continuations of my narrative ("Crosby is hipchecked into the sun and falls, Icarus-like, and all 93-million miles worth, into the sea"). On the basis of such symbolic variations and continuations, I can choose to visually simulate an entertained state of affairs to a greater or lesser degree of vividness, as when reading a novel one may imagine in greater or lesser detail what is being described.

Whether the difference here noted between the paradigmatic functioning of the word and the tool is a difference in degree or kind, however, must now be considered.

\section{Differences in kind or degree?}

In the preceding sections, I have discussed respects in which words and tools have a similar horizonal structure rooted in perception and action. It has often been argued that there are definitive characteristics of language that distinguish it from non-linguistic modes of cognition. On the basis of the preceding considerations, however, such exceptionalism can be challenged. In this section, I emphasize differences in degree and similarities between operating with signs and objects where others have seen differences in kind. These considerations form part of a larger argument in favor of a continuity between action and perception involving objects, on the one hand, and language use, on the other, to be elaborated in this and the following two sections.

With its preeminently empty outer horizons, which can be "actualized" in imagination just as easily or even more easily than in perception, words, we might say, are like tools of the imagination. The linguist Charles Hockett identified displacement, the ability of language to direct us to what is not present in the here and now, as one of the distinguishing properties of human language (Hockett 1963). Note, however, that it is not clear whether this ability to orient us towards the absent should be viewed as a difference in kind between the mighty word and the more modest tool, or merely as a difference in primary function, with tools and words both possessing horizons of virtuality to varying degrees. The tool, too, as we have seen, has its empty horizons, and can direct us imaginatively and memorially towards what is not and cannot be presented in actuality. The hockey stick is also a symbol, and the world, as Augustine remarks, is full of signs. Conversely, words are often meant to direct our attention to what is present in the immediate environment and they play a vital role in the flow of practical activity. Indeed, even if this "online" use happens not to be the statistically most prevalent use of language in the day-to-day life of a competent language-user, it could still be argued that it is in some essential respects foundational for "offline" uses of words.

Another point of similarity is that even though the empty horizons of the word in normal discourse are less constrained by real, causal relations than those of the tool, in our learning history, it is plausible that the horizons of both are shaped by similar mechanisms that have become sedimented into habitual associations. To name just one prominent mechanism, the outer practical horizons of the hammer are plausibly formed genetically through relations of 
relevance and contiguity into which I have seen the hammer enter, or in which I myself have employed the hammer, in the past: the hammer refers to nails and lumber because I have seen it come into and brought it into meaningful causal contact with these. Similarly, the horizons of the word "hammer" are laid down primarily in early experiences with both the word and the object when the two come into a relation of multi-modal contiguity: as a child, I heard the word "hammer" when the hammer was salient in the intersubjective and practical context. Through this association, the word continues to emptily refer to the hammer even in the latter's absence, just as the hammer continues to refer to nails and lumber even when there are none to be found in the actual perceptual horizon. ${ }^{27}$

It might be objected that the word "refer" is being employed equivocally in the case of the hammer "referring" to nails and lumber, on the one hand, and the case of the word "hammer" referring to hammers, on the other. It may appear that what phenomenologists, following Heidegger, have in mind when they speak of the hammer referring to nails and lumber has little to do with what mainstream philosophers of language, following Frege, have in mind when discussing the referential relationship between the sign and the object it denotes. ${ }^{28}$ My reply, which I can only state in outline here, is that the referential character of the sign is a refinement of the referential character of the tool, and of perceptual objects more generally. We by and large treat signs as tools whose specific job it is to refer (in a broad sense of that term). Removed from the rest of our practical engagement with the world, the referential character of the sign can be exploited and rendered much more precise than it is in tools or objects that live their own lives, as it were, and have other roles to fill outside of the specific task of referring. Signs are like highly specialized referring tools, much more like a specific tool for bicycle repair that serves only one function than like an all-purpose hammer or saw. But in treating signs as such, we are not investing them with a radically new characteristic that no other perceived phenomenon possesses. Rather, we are exploiting and refining the referential, relational quality common to all perceptual experience. Occasionally an object comes to take on something approaching this specificity of reference for us. A piece of clothing or jewellery may always call to mind the absent lover who gifted it just as much as the lover's name itself does. The term "reference," then, is not being predicated equivocally in the two cases. Rather, it is predicated analogically, where analogy is here understood in the sense of being united through a common meaning. ${ }^{29}$

Consider another respect in which the spoken word initially appears to be radically different from the tool, but where upon further reflection, a similarity is revealed. Structuralist linguistics emphasizes that the word belongs to a language system within which the signification of any one word is determined by its proximity, juxtaposition, and differentiation vis-à-vis the rest of the signs in the system. Some structuralists and poststructuralists took this insight so far as to claim that the signification of a sign is to be found solely in negativity and difference, in the contrast of one sign against all the others in a system. It may appear on first blush that the hand-tool, by contrast, stands there in

\footnotetext{
${ }^{27}$ Di Paolo et al. 2018 have developed a non-representational, enactivist account of reference complementary to the phenomenological account developed here. See especially chapters 8 and 11.

${ }^{28}$ The term from Heidegger's Being and Time that I here translate as "reference" is Verweisung, while in Frege's canonical sense-reference distinction (Frege), the term usually rendered in English as "reference" is Bedeutung.

${ }^{29}$ This is the sense of analogy Aristotle has in mind when he says that "being" is predicated analogously. See Metaphysics 4.2 (1003a33-35).
} 
pure positivity, its "meaning" given in itself, as it were. But as we have seen, the sense of the tool, too, is codetermined by the relations within which it stands in a totality of other tools, materials, and projects: the "meaning" of the hammer, we can say, is the specific function that it performs within the equipmental totality, a function that the saw, nails, plyers, and screwdrivers precisely do not perform. To that extent, its functional value, too, is determined through its differential relations to other tools and materials.

Just as we make the tool more like the word by recognizing that its "significance" is determined in part through negativity, we can also challenge the structuralist (or poststructuralist) position that the signification of a sign in a sign system is determined solely through negative relations to other signs. Associations that sign-users form between signs and, paradigmatically, their referents, may play a "positive" role in determining the meaning of signs. If we avoid the extreme, solely negative reading of structuralism, it is easy to see how structuralism and phenomenology can be reconciled on object and sign perception. It is no accident that when the phenomenologist Merleau-Ponty began reading structuralist works in the middle of his career, he saw in the differential nature of the sign not a characteristic unique to language, but rather a structural resource for describing perception more generally. The thoroughly relational characteristic of sign meaning in de Saussure must have struck Merleau-Ponty as something like an analog to the holistic, relational account of perception inspired by phenomenology and Gestalt psychology that he had already been developing in his early works. ${ }^{30}$

Finally, one might think that the syntactical properties of words constitute unique characteristics quite different in kind from any properties that characterize tools and their use. But here again we find that such characteristics are not without their counterpart at a more foundational level of experience. The patterns of interaction that we engage in when using tools can be seen as structured by an "action grammar" that is analogous to that of linguistic grammar more narrowly construed. Indeed, it has been argued that there may even be a coevolution between the development of the cognitive resources required for procedural tool and object manipulation and manufacture, and the cognitive structures that underwrite linguistic syntax. ${ }^{31}$ Such accounts may offer a more plausible, gradualist account of the emergence of the language faculty out of preceding, more foundational cognitive abilities than saltatory accounts that posit the sudden emergence of a modular language faculty with little or no evolutionary precedent.

These considerations are important for understanding the continuity between words and other kinds of perceptual object, which I will pursue at greater length in the following sections. For now, I want to emphasize that the comparison is not merely an empty, formal analogy or metaphor, but rather that these are concrete, phenomenal similarities.

\section{Convergences with recent Neurolinguistics}

In this section, I will briefly explore convergences between the phenomenological account of word horizons I have provided thus far and recent behavioral and neuroimaging

\footnotetext{
${ }^{30}$ On the reconciliation of structuralist and phenomenological ideas approaches, especially in the work of Merleau-Ponty, see Silverman 1997; Stawarska 2015. David Abram (1997) has also emphasized the relational nature of perception in his work on Merleau-Ponty.

${ }^{31}$ See, e.g., McGinn's (2015) “grip-action theory” of the emergence of syntactic and referential characteristics of language.
} 
research on language processing. What we find, I argue, is a "mutual enlightenment" (cf. Gallagher 1997) between these two perspectives on language perception and processing. Stated somewhat crudely, the theory emerging from this recent research is the following: (1) perceiving (an object) and acting (with an object), (2) imagining and recalling such perceiving or acting, and (3) processing language associated with such perceiving or acting all employ the same broad underlying neurobiological networks, somatotopic sensorimotor networks in particular. Where language is concerned, these underlying networks make up the neurobiological counterpart of the phenomenon described above where perceiving a word or sentence associated with (for example) a concrete object elicits a horizon of sensorimotor and affective associations akin to the one elicited by perceiving or interacting with the object itself. A host of neuroimaging, cognitive, and behavioral studies performed in recent decades support this view. ${ }^{32}$ Here I will mention just two relevant aspects of this research.

Psychologists have long known that active, offline mental visualization interferes with the processing of corresponding real, online visual information. In the canonical experiments, subjects were asked to visualize common objects while looking at a blank white screen. After several trials, dim actual images of the objects were projected onto the screen where the subjects were projecting their own visualizations. Subjects often were unable to distinguish real images from their visualizations. This is known as the Perky Effect, after its discoverer, Mary Perky (1910). Researchers have now discovered that the Perky Effect is present not only in active mental visualization, but also when subjects merely process language whose corresponding visualizations would interfere with the relevant actual visual information. In one study (Bergen et al. 2007), subjects faced a blank computer screen and heard spoken sentences for some concrete state of affairs that would have a canonical location: Ex hypothesi, "the grass glistened" should elicit visual imagery in the lower sector of the screen, while "the sky darkened" should elicit imagery in the upper sector. The experimenters found that subjects showed significantly decreased reaction time when asked to identify actual visual information presented in the segment of the visual field corresponding to the canonical locations of the simultaneously presented linguistic stimulus, but not for other parts of the field. This suggests that linguistic input is eliciting location-specific visual simulations.

In a neuroimaging study, Hauk et al. (2004) showed that passively reading action words involying the face, arms, and legs differentially activated areas of the primary motor cortex for the corresponding activities. Reading the word "lick" activated corresponding motor areas for face and mouth, while "kick" activated motor areas associated with the legs. Similarly, processing nouns for objects associated with common motor activities also activates the associated motor regions (Marino et al. 2014). Language processing, then, elicits not only perceptual imagery, but also motor imagery. Similarly, Marino et al. (2014) found in a go, no-go experiment that subjects responded more slowly to noun stimuli for graspable versus non-graspable objects. The authors take this as evidence that subjects were relying on activation of motor systems to determine whether the object named by the noun stimulus was graspable or not. This activation interfered with employing the same motor system to respond to the stimuli, hence resulting in slower response time to noun stimuli referring to graspable objects than to noun stimuli referring to non-graspable objects (cf. Bergen 2012).

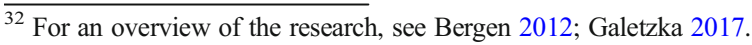


What is the relevance of these findings for the phenomenological account of word horizons developed above? I believe the empirical work provides a degree of corroboration for the phenomenological account by showing us the neural correlates of the phenomena. The subpersonal sensorimotor activation we see in passive word processing corresponds to what Husserl referred to as the passive "awakening" (what I have also referred to as "eliciting") of a horizonal possibility. In hearing the term "hockey stick," all other things being equal, I run a dim sensorimotor simulation of some of the relevant perceptual and motoric features of seeing or interacting with a hockey stick. If we attend to our experience of language processing, we may find that we are liminally aware of such fleeting elicitations. Especially evocative and image-rich forms of language such as literature often make this power of language more salient for us (cf. Gosetti-Ferencei 2018, ch.6). But in this respect, literature is different from more banal uses of language in degree, not in kind. ${ }^{33}$

\section{6 "Scaling-up" through the horizons of the word}

The preceding discussion has consequences for a problem confronted by recent embodied approaches to cognition: the so-called "scaling-up" problem (see Gallagher 2017; Kiverstein and Rietveld 2018). The scaling-up problem concerns the relationship between lower and higher modes of cognition - between perception and action, on the one hand, and thinking, memory, imagination, planning, and language use, on the other. Perception and action are "online" modes of cognition, directly engaging their object "in the flesh," as phenomenologists sometimes say, while thinking, memory, imagination, and planning can operate offline, entertaining objects or states of affairs that are non-existent, spatiotemporally absent, or abstract. While it is one thing to provide an embodied, non-representational account of perception and action, forms of cognition in which, as Rodney Brooks (1991) famously put it, the world can serve as its own best model, it may be quite another task to explain modes of cognition that deal with nonexistent, absent or abstract states of affairs and properties. Such forms of cognition are said to be "representation-hungry" (Clark and Toribio 1994): they seem to demand representations that stand in for what perception itself cannot provide. Clearly, then, the scaling up problem is particularly acute for non-representationalist theories of cognition, such as recent embodied, extended, embedded, and enactive (4E) approaches. Some skeptics are willing to grant that $4 \mathrm{E}$ approaches have made admirable headway on explaining perception and action without reliance on inner representations. They doubt, however, that one can explain higher modes of cognition, for which the features of the world under consideration are not being provided by the world itself online via perception, through the same processes and mechanisms (e.g., Shapiro 2014).

Responses to the scaling-up problem from advocates of 4E approaches usually take the following form. The differences between higher and lower, online and offline cognition should not be taken as absolute. Rather, we should understand how the higher, offline cognition is integrated into, dependent upon, and continuous with lower, online cognition. One popular strategy involves treating episodic visual memory and

\footnotetext{
${ }^{33}$ In this section, I have focused primarily on empirical research into the sensorimotor aspects of language processing. On the emotional aspects, see Glenberg et al. 2009; Havas et al. 2007. On the interpersonal aspects, see Gallese 2008; Fuchs and de Jaegher 2009; Cuffari et al. 2015.
} 
imagination, for example, as re-enactments of originally enacted online, bodilyperceptual experiences, or portions thereof. ${ }^{34}$ When I call to mind the visual image of the house I grew up in, I am re-enacting past perceptual experiences. But if those original perceptual experiences were not representational, then neither is their reenactment (Kiverstein and Rietveld 2018). More generally, Gallagher emphasizes that our acquired ability to imagine may be rooted in developmentally prior practices of acting out our pretenses in symbolic and pretend play (Gallagher 2017).

Assuming such approaches are on the right track, how do things stand for language? If ever there were a cognitive ability whose explanation would seem to demand a difference in kind in our basic cognitive makeup, language would have a strong prima facie claim to be it. Less work has been done thus far by proponents of 4E cognition to explain how our linguistic ability can be understood as continuous with more basic, representation-free modes of cognition such as perception and action. Inspired by ecological psychology, some enactivists propose thinking of language as having something of the relational affordance-structure of natural objects more generally. Thus, Gallagher writes that "Pragmatically considered, concepts or thoughts can be regarded as nothing other than affordances that offer (or solicit us to) possibilities to follow one path or another as we engage in thinking," continuing that this process is most often scaffolded by language (2017, 195 f.). Kiverstein and Rietveld likewise speak of the "affordances of a linguistically structured environment" that allow for engaging in "abstract and symbolic modes of cognition" (Kiverstein and Rietveld 2018; cf. Rietveld et al. 2018).

Such suggestions are by and large complementary to the account I have proposed. They are on the right track, but there is much work to do to spell out the programmatic promise of such indications. In the meantime, there is a very real danger that critics will simply dismiss such talk as empty metaphor, a formal analogy that fails to illuminate in any explanatory way the purportedly continuous relationship between lower and higher modes of cognition. ${ }^{35}$ Even if there is some illustrative value to the analogy, pending further elaboration of the proposal, there is as yet no reason to assume that perception and action are genuinely continuous with our linguistic facility. After all, the concept of an affordance was fashioned paradigmatically to describe how features of the material environment present possibilities of action and perception to an animal depending on that animal's intentions, needs, and bodily skills of perception and action. It is not clear how such a notion bears on our linguistic facility.

My proposal responds to this objection by clarifying the sense in which language, too, belongs to our phenomenally experienced "sociomaterial" environment (van Dijk and Rietveld 2017; cf. Gahrn-Andersen 2019). My emphasis on language as first and foremost a spoken, perceived phenomenon restores language to the material cultural world alongside more earthy artifacts such as tools. As such, it now becomes clear how a notion such as that of an affordance or horizon could apply to spoken language as much as to more obviously material items such as extended spatiotemporal objects. Once we recall that language, too, is a perceived phenomenon and has its own proper materiality, we can see how we are not merely trading in metaphors when we speak of perceived

\footnotetext{
${ }^{34}$ E.g., Thompson 2007. This strategy follows Husserl's distinction between presentational acts such as perception that render something originally present (Gegenwärtigung) and secondary acts, dependent on these, which re-present such original acts (Vergegenwärtigung).

${ }^{35}$ Kiverstein and Rietveld (in press) are aware of this concern.
} 
language as affording one or another continuation of thought, imagination, action, or perception. Further, as we have seen, this continuity on the level of phenomenological description has its counterpart on the level of neurological processing in the overlap of sensorimotor brain regions involved in action and perception, imagination, and linguistic comprehension. And as I have argued above, there is genuine continuity between key features of perceived objects and properties of language, such as displacement, syntax, and the negativity of the signifier, often assumed to be unique to language.

We see, then, that there is a significant similarity between ecological psychologyinspired talk of the affordance structure of language, and my own phenomenologicallyinspired account of the horizonal structure of language. While both are terms of art, I prefer the language of horizons as it was designed to encompass associative relations spanning our entire experiential life and not merely its practical and perceptual features. As such, it more naturally allows for extension to include the horizons of language. Indeed, some ecological psychologists have argued on principled grounds against the overextension of the notion of affordance into the domain of conventional usage that we enter with language. Thus Golonka (2015) argues that since affordances, in the strict sense, involve "law-based" information and relationships between perceiver and environment, overextending the notion to include conventional relations threatens the rigor of the concept of an "affordance" and undermines ecological psychology's account of direct perception. ${ }^{36}$ By contrast, the phenomenological notion of the horizon has no terminological baggage that would prevent its extension into the domain of language. ${ }^{37}$

I will conclude this section with a brief programmatic comment on the status of the debate surrounding the continuity or discontinuity between lower and higher modes of cognition, and the contribution the present paper makes to it. At times it is difficult to assess what would or would not count as an argument for or against continuity. The difficulty here may not be that we do not have any clear and relevant ways of talking about continuity, but rather that we have too many and tend to conflate them. Further, that insidiously polysemous term "representation" works its way into many of these discussions, but without being univocally applied in the various contexts. In the interest of clarifying the discussion, I propose the following ways of discussing continuity. I do not claim that the list is comprehensive.

1. Phenomenal Continuity. One can argue for phenomenal continuity between two modes of cognition simply by describing their essential concrete structures. If the same concretely described structures are at play in two purportedly distinct modes of cognition, and no other essential structures can be identified that distinguish them, we needn't regard them as radically distinct. In this paper, I have argued that experiences of language and of interaction with tools both belong to the same domain of bodily, perceptual-actional experience broadly construed. Since both exhibit the same essential structures and concrete phenomenality, the argument for continuity consists simply in describing and analyzing both phenomena in terms of these same structures. Where language is concerned, the primary mode of experiencing language is the presented, perceived word. Is language thus construed

\footnotetext{
${ }^{36}$ Kiverstein and Rietveld (in press) respond to this objection.

${ }^{37}$ Nöe (2004) has already noted the similarities between ecological psychology's affordances and phenomenology's horizons. However, see Pepper 2014 for reasons to be cautious about confounding the two.
} 
"representational"? By prompting explicit memorial or imaginative episodes, perceived words prime re-enactments (Vergegenwärtigungen, or re-presentations, in Husserl's idiom) of memorial or imagined perceptual experience, as described above (Section 3). And symbols such as spoken, gestured, or written words can be said to "represent," or stand in for (Vertreten), their referents. But in this regard, words are not essentially different from other perceptual phenomena. These latter two senses of "representation" have little to do with the sense that is prevalent in the cognitive sciences and that is at the heart of the continuity-discontinuity debate.

2. Neurobiological Continuity. An argument for phenomenal continuity does not necessarily entail anything concerning the underlying neurobiological correlates of the phenomena. However, if there is a significant coincidence between the neural networks associated with perception and action, on the one hand, and language processing and production, on the other, then there is strong albeit inconclusive evidence for the following claims: (a) there is an underlying continuity of systems and mechanisms involved; and (b) if perception and action do not rely on neurologically instantiated representations then the same will hold for language, and vice versa. So, if enactive and embodied non-representational accounts of perception and action are on the right track, then given the coincidence between systems involved in language, perception, and action (see Section 5), there is good reason to infer that language systems in the brain do not operate on mental representations. ${ }^{38}$ Note that "mental representation" here refers to the internal symbolic representations posited by classical cognitive science. This usage is equivocal with that of the two senses of "representation" just discussed as relevant for phenomenal continuity.

3. Developmental Continuity. If the underlying mechanisms of language processing and production are continuous with those of action and perception, then we should expect to see rich, concrete continuities and feedback between the development of these abilities in ontogenesis, with sensorimotor development enabling and constraining developments in social cognition, social perception, and language. ${ }^{39}$

4. Evolutionary Continuity. Similarly, neurobiological continuity would seem to predict an account of the evolution of the human language ability that emphasizes its environmental embeddedness and its sensorimotor anchoring. This view is consistent with theories that propose an origin of verbal language in bodily gesture (Armstrong and Wilcox 2007) and tool use (Byers 1999; Holloway 2012; Brozzoli et al. 2019), while it conflicts with accounts of language evolution that claim our language faculty is a unique cognitive module that evolved with an abrupt genetic mutation (Berwick and Chomsky 2015).

In the preceding pages, I have argued directly for (1) on phenomenological grounds and sought support for (2) from recent psycholinguistic research. My proposal predicts (3)

\footnotetext{
$\overline{38}$ A weaker argument by analogy is also available here, one that does not rely on any particular findings from neurolinguistics: Language processing exhibits the same essential phenomenal structures as action and perception; Action and perception do not rely on mental representations; Therefore, language processing does not rely on mental representations. The argument is weak because the nature of underlying neuobiological structures is not evident to phenomenal consciousness.

39 This has not been the topic of the present paper. But see Di Paolo et al. 2018, especially ch. 9, and Kee 2019.
} 
and (4) and would receive some corroborating, abductive support from independent evidence in favor of them. ${ }^{40}$

\section{Conclusion}

Responding to the scaling-up problem requires bridging the gap between supposedly "lower" and "higher," online and offline modes of cognition. The bridging strategy advocated in this paper involves building the bridge from both sides, as it were. Working from the one shore, I have attempted to show that "lower" cognition, such as perception and action involving tools and objects more generally, already involves some characteristics of "higher" cognition in rudimentary form. The perceptual world is already rich with holistic and differential relationships between objects, references to what is not immediately given, and a sort of proto-grammaticality implicit in our interactions with the world. Working from the other shore, I have drawn attention to the fact that language, a paradigm example of "higher" cognition, is also an embodied, perceptual achievement, sharing many commonalities with more basic modes of perception and action. To put it somewhat crudely, I propose bridging between higher and lower cognition by smartening up perception and action and dumbing down language.

Numerous avenues for further inquiry are outlined by the present paper. I will now close by addressing a potential concern and indicating some directions for further inquiry.

One could raise the concern that taking the comparison of language with the tool as literally as I have risks instrumentalizing language, or otherwise treating it in a reductionist manner. Heidegger (1982), among others, voiced the concern that treating language as a means misses the formative role it plays in shaping thought and experience. This concern, however, applies to accounts that view language as playing the merely instrumental, vehicular role of communicating a content (whether this be understood as a thought, experience, or representation) that is otherwise independent of the means through which it is communicated. My view of the instrumentality of language, by contrast, emphasizes the perceptual-horizonal mediality of language is essential to language as such and that higher achievements of cognition continue to be informed by this foundational medium. The merely instrumental, vehicular view treats the relationship between the content expressed in language and the means of expression as external. My account, by contrast, sees the medium as internally related to the content expressed (cf. Kee 2018). ${ }^{41},{ }^{42}$

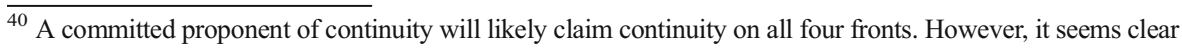
that one can be committed to phenomenal continuity while denying neurobiological, developmental, and evolutionary continuity. Whether it is possible to mix and match continuity and discontinuity across all four facets would have to be assessed on a case-by-case basis.

${ }^{41}$ Another way of bringing out the uniqueness of the medium is to draw attention to the open, indeterminate domain of possibilities that the instrumental character of language opens to us. As Merleau-Ponty puts it, if language is a tool, it is more like a musical instrument, allowing for an open number of new and surprising possibilities, than it is like a hammer that only allows for a limited range of use (1973, 92; cf. 2012, 192; Wittgenstein 2009, §6). One might reply here, however, that Merleau-Ponty underestimates the range of novel applications to which one can apply the hammer.

${ }^{42}$ Cf. Taylor's (2016) distinction between "constitutive" and "framing" theories of language. I take mine to fall into the former camp, whereas the "merely instrumental" account is a framing theory.
} 
The horizonal account of perception I have elaborated brings imagination and perception into the most intimate relation. The horizonal content that I have described as being dimly activated or appresented along with perception can be seen as an achievement of "weak imagination" (Lohmar 2008, 2010) which complements perception. Further, such implicit and involuntary contributions of weak imagination can prime and prompt more deliberate, explicit acts of "strong" imagination - re-presentational episodes in which we explicitly re-enact (i.e., imagine or remember) more vivid, determinate content. At the same time, by placing language, the preeminent tool of rationality, firmly within the domain of perception, I am drawing an intimate connection between perception and reason. These themes are not new to contemporary and classical phenomenology. ${ }^{43}$ By emphasizing the perceptual phenomenality of language, however, my approach adds a new dimension to the rootedness of the rational in the aesthetic. What consequences this might have for the phenomenological account of rationality, however, are not immediately clear. The topic warrants further exploration.

In my typology of horizons of the word, I list an actual intersubjective outer horizon. I have done little thus far, however, to characterize its role and elaborate its significance for our perception and understanding of speech. Further, I have not considered the possible role of an empty intersubjective outer horizon: a reference to interlocutors, both general and specific, and their influence on us even in language processing involving different actual interlocutors or no actual interlocutors whatsoever (such as in the neuroimaging cases, where the listening subject is in an MRI machine). Admittedly, the referential outer horizon includes an indirect reference to intersubjectivity, as it will be implied in the outer horizon of the referential intention. However, with my focus on the referential outer horizon (which directs us preeminently though not exclusively to the external world), I have downplayed the extent to which speech perception preeminently (though, again, not exclusively) involves a relation to a concrete other. Indeed, above, in the interest of being able to say something in general about the empty outer horizon of the word, I have temporarily quite deliberately bracketed the involvement of the other. Under normal circumstances, this concrete other speaks not only to refer, but also to express herself and establish an affective rapport between speaker and hearer. As usage-based approaches to language acquisition emphasize, our acquisition of a referential system of language is thoroughly intertwined with and founded upon our precocious social cognition (Tomasello 2003). If this is so, then the horizons of our lexica, which are first laid down in early acquisition, are likely thoroughly permeated by intersubjectivity. ${ }^{44}$

I have also focused primarily on speech perception rather than production. The former is a more passive operation (though it also requires active attention and interpretation), while production is a paradigmatically active task that always involves a greater or lesser degree of creativity. Plausibly, speech production will have a horizonal structure similar to that of speech perception. However, what motivates a speaking subject to light upon just one sentence from the logically infinite possible

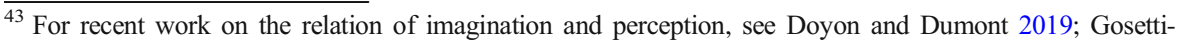
Ferencei 2018; Lennon 2015. On the aesthetic-perceptual basis of the rational, see Romano 2015.

${ }^{44}$ See Di Paolo et al. 2018, especially chapter 8. Cf. Bottineau 2010, 283 f.: "It is impossible to draw a general semantic theory on the basis of a simple subject-world relation: what is at stake is a world-based subjectsubject relation."
} 
sentences is a question that remains both empirically and phenomenologically little understood.

These, however, I view as positive challenges, indications that the research program I have outlined here presents a fecund ground for further fruitful inquiry.

Acknowledgments I would like to express my gratitude to Michael Malay, Saulius Geniusas, Dieter Lohmar, Jagna Brudzińska, Erik Rietveld, Julian Kiverstein, John Drummond, Dan Zahavi, James Jardine, and Thomas Szanto, as well as two anonymous reviewers from Phenomenology and the Cognitive Sciences, for comments on previous versions of this paper.

\section{References}

Abram, D. (1997). The spell of the sensuous: Perception and language in a more-than-human world. New York: Vintage.

Armstrong, D. F., \& Wilcox, S. E. (2007). The gestural origin of language. Oxford: Oxford University Press. Bergen, B. K. (2012). Louder than words: The new science of how the mind makes meaning. New York, NY: Basic Books.

Bergen, B. K., Lindsay, S., Matlock, T., \& Narayanan, S. (2007). Spatial and linguistic aspects of visual imagery in sentence comprehension. Cognitive Science, 31(5), 733-764. https://doi.org/10.1080 /03640210701530748.

Berwick, R. C., \& Chomsky, N. (2015). Why only us: Language and evolution. Cambridge, MA: The MIT Press.

Bottineau, D. (2010). Enaction and language. In J. Stewart, O. Gapenne, \& E. A. Di Paolo (Eds.), Enaction: Toward a new paradigm for cognitive science (pp. 267-306). Cambridge, MA: The MIT Press.

Brooks, R. A. (1991). Intelligence without representation. Artificial Intelligence, 47(1), 139-159. https://doi. org/10.1016/0004-3702(91)90053-M.

Brozzoli, C., Roy, A. C., Lidborg, L. H., \& Lövdén, M. (2019). Language as a tool: Motor proficiency using a tool predicts individual linguistic abilities. Frontiers in Psychology, 10. https://doi.org/10.3389 /fpsyg.2019.01639.

Byers, A. M. (1999). Communication and material culture: Pleistocene tools as action cues. Cambridge Archaeological Journal, 9(1), 23-41. https://doi.org/10.1017/S0959774300015195.

Clark, A., \& Toribio, J. (1994). Doing without representing? Synthese, 101(3), 401-431. https://doi. org/10.1007/BF01063896.

Cowley, S. J. (2014). Linguistic embodiment and verbal constraints: Human cognition and the scales of time. Frontiers in Psychology, 5(October). https://doi.org/10.3389/fpsyg.2014.01085.

Cuffari, E. C., di Paolo, E., \& de Jaegher, H. (2015). From participatory sense-making to language: There and Back again. Phenomenology and the Cognitive Sciences, 14(4), 1089-1125.

Derrida, J. (1981). Plato's pharmacy. In B. Johnson (Ed.), Dissemination (pp. 63-171). Chicago: University Of Chicago Press.

Deutscher, G. (2005). The unfolding of language: An evolutionary tour of Mankind's greatest invention. New York: Metropolitan Books.

Di Paolo, E. A., Cuffari, E. C., \& de Jaegher, H. (2018). Linguistic bodies: The continuity between life and language. Cambridge, MA: The MIT Press.

van Dijk, L., \& Rietveld, E. (2017). Foregrounding sociomaterial practice in our understanding of affordances: The skilled intentionality framework. Frontiers in Psychology 7. https://doi.org/10.3389 /fpsyg.2016.01969.

Doyon, M., \& Dumont, A. (Eds.). (2019). The imagination: Kant's phenomenological legacy (Vol. 17) The New Yearbook for Phenomenology and Phenomenological Philosophy.

Dretske, F. (1969). Seeing And Knowing. Chicago: University Of Chicago Press.

Frege, G. (1948). Sense and reference. Philosophical Review, 57(3), 209-230.

Fuchs, T., \& de Jaegher, H. (2009). Enactive intersubjectivity: Participatory sense-making and mutual incorporation. Phenomenology and the Cognitive Sciences, 8(4), 465-486.

Gahrn-Andersen, R. (2019). But language too is material! Phenomenology and the Cognitive Sciences, 18(1), 169-183. https://doi.org/10.1007/s11097-017-9540-0. 
Galetzka, C. (2017). The story so far: How embodied cognition advances our understanding of meaningmaking. Frontiers in Psychology 8. https://doi.org/10.3389/fpsyg.2017.01315.

Gallagher, S. (1997). Mutual enlightenment: Recent phenomenology in cognitive science. Journal of Consciousness Studies, 4(3), 195-214.

Gallagher, S. (2017). Enactivist interventions: Rethinking the mind. Oxford: Oxford University Press.

Gallese, V. (2008). Mirror neurons and the social nature of language: The neural exploitation hypothesis. Social Neuroscience, 3(3-4), 317-333. https://doi.org/10.1080/17470910701563608.

Geniusas, S. (2012). The origins of the horizon in Husserl's phenomenology. Contributions to phenomenology. Springer Netherlands.

Glenberg, A. M., Webster, B. J., Mouilso, E., Havas, D., \& Lindeman, L. M. (2009). Gender, emotion, and the embodiment of language comprehension. Emotion Review, 1(2), 151-161. https://doi.org/10.1177 $/ 1754073908100440$.

Golonka, S. (2015). Laws and Conventions in language-related behaviors. Ecological Psychology, 27(3), 236250. https://doi.org/10.1080/10407413.2015.1068654.

Gosetti-Ferencei, J. A. (2018). The life of imagination: Revealing and making the world. Columbia University Press.

Gurwitsch, A. (2010). The collected works of Aron Gurwitsch (1901-1973): Volume III: The field of consciousness: Theme, thematic field, and margin. Edited by Richard M. Zaner. Phaenomenologica 194. Dordrecht: Springer.

Hauk, O., Johnsrude, I., \& Pulvermüller, F. (2004). Somatotopic representation of action words in human motor and premotor cortex. Neuron, 41(2), 301-307. https://doi.org/10.1016/S0896-6273(03)00838-9.

Havas, D. A., Glenberg, A. M., \& Rinck, M. (2007). Emotion simulation during language comprehension. Psychonomic Bulletin \& Review, 14(3), 436-441. https://doi.org/10.3758/BF03194085.

Heidegger, M. (1962). Being and time. Translated by John Macquarrie and Edward Robinson. New York: Harper \& Row.

Heidegger, M. (1982). On the way to language. Translated by Peter D. Hertz. New York: Harper \& Row.

Hockett, C. (1963). The problem of universals in language. In In Universals in Language, edited by Joseph Greenberg. Cambridge, MA: The MIT Press.

Holloway, R. L. (2012). Language and tool making are similar cognitive processes. Behavioral and Brain Sciences, 35(4), 226-226. https://doi.org/10.1017/s0140525x11002019.

Husserl, E. (1959). Erste philosophie (1923/24): Zweiter teil: Theorie der phänomenologischen reduktion. Edited by Rudolf Boehm. Husserliana, VIII. Den Haag: Martinus Nijhoff.

Husserl, E. (1964). Phenomenology of internal time consciousness. Edited by Martin Heidegger. Translated by James S. Churchill. Bloomington: Indiana University Press.

Husserl, E. (1969). Formal and transcendental logic. Translated by Dorion Cairnes. The Hague: Martinus Nijhoff.

Husserl, E. (1973). Experience and judgment: Investigations in a genealogy of logic. Translated by K. Ameriks and J. Churchill. Evanston: Northwestern University Press.

Husserl, E. (1977). Cartesian meditations: An introduction to phenomenology. Martinus Nijhoff Pub: Translated by Dorion Cairns. Lexington KY.

Husserl, E. (1982). Ideas pertaining to a pure phenomenology and to a phenomenological philosophy: First book: General introduction to a pure phenomenology. Translated by F. Kersten. The Hague: Springer.

Husserl, E. (1989). Ideas pertaining to a pure phenomenology and to a phenomenological philosophy: Second book: Studies in the phenomenology of constitution. Translated by R. Rojcewicz and A. Schuwer. The Hague: Springer.

Irwin, B. A. (2017). An enactivist account of abstract words: Lessons from Merleau-Ponty. Phenomenology and the Cognitive Sciences, 16(1), 133-153. https://doi.org/10.1007/s11097-015-9434-y.

James, W. (1890). The principles of psychology. Cambridge: Harvard University Press.

Kee, H. (2018). Phenomenology and ontology of language and expression: Merleau-Ponty on speaking and spoken speech. Human Studies, 41(3), 415-435. https://doi.org/10.1007/s10746-018-9456-x.

Kee, H. (2019). Pointing the way to social cognition: A phenomenological approach to embodiment, pointing, and imitation in the first year of infancy. Journal of Theoretical and Philosophical Psychology. https://doi. org/10.1037/teo0000130.

Kiverstein, J., \& Rietveld, E. (In press). Scaling-up skilled intentionality to linguistic thought.”

Kiverstein, J., \& Rietveld, E. (2018). Reconceiving representation-hungry cognition: An ecological-enactive proposal. Adaptive Behavior, 26(4), 147-163.

Kwan, T.-W. (1990). Husserl's concept of horizon: An attempt at reappraisal. In The moral sense and its foundational significance: Self, person, historicity, community: phenomenological praxeology and 
psychiatry, edited by Anna-Teresa Tymieniecka, 361-99. Analecta Husserliana. Dordrecht: Springer Netherlands. https://doi.org/10.1007/978-94-009-0555-9_30.

Lakoff, G., \& Johnson, M. (1999). Philosophy in the flesh. New York: Basic Books.

Lennon, K. (2015). Imagination and the imaginary. London: Routledge.

Lohmar, D. (2008). Phänomenologie Der Schwachen Phantasie - Untersuchungen Der Psychologie, Cognitive Science, Neurologie Und Phänomenologie Zur Funktion Der Phantasie in Der Wahrnehmung. Dordrecht: Springer.

Lohmar, D. (2010). The function of weak phantasy in perception and thinking. In D. Schmicking \& S. Gallagher (Eds.), Handbook of phenomenology and cognitive science (pp. 159-177). Dordrecht: Springer Netherlands. https://doi.org/10.1007/978-90-481-2646-0_9.

Marino, B. F. M., Sirianni, M., Volta, R. D., Magliocco, F., Silipo, F., Quattrone, A., \& Buccino, G. (2014). Viewing photos and reading nouns of natural graspable objects similarly modulate motor responses. Frontiers in Human Neuroscience, 8. https://doi.org/10.3389/fnhum.2014.00968.

McGinn, C. (2015). Prehension: The hand and the emergence of humanity. Cambridge, Mass: The MIT Press. Merleau-Ponty, M. (1963). The structure of behavior. Translated by Alden L. Fisher. Boston: Beacon Press.

Merleau-Ponty, M. (1973). Consciousness and the acquisition of language. Translated by Hugh J. Silverman. Evanston: Northwestern University Press.

Merleau-Ponty, M. (2012). Phenomenology of perception. Translated by Donald Landes. New York: Routledge.

Nöe, A. (2004). Action in perception. Cambridge, Mass: MIT Press.

Pepper, K. (2014). "The phenomenology of sensorimotor understanding." In Contemporary sensorimotor theory, edited by John Mark Bishop and Andrew Owen Martin, 53-65. cham: Springer.

Perky, C. W. (1910). An experimental study of imagination. The American Journal of Psychology, 21, 422452.

Quepons, I. (2015). Intentionality of moods and horizon consciousness in Husserl's phenomenology. In Feeling and value, willing and action: Essays in the context of a phenomenological psychology, edited by Marta Ubiali and Maren Wehrle, 93-103. Phaenomenologica. Cham: Springer International Publishing. https://doi.org/10.1007/978-3-319-10326-6_6.

Quepons, I. (2016). Horizonte y temple de ánimo en la fenomenología de Edmund Husserl. Revista de filosofia DIÁNOIA, 61(76), 83-112. https://doi.org/10.21898/dia.v61i76.5.

Rietveld, E., Denys, D., \& Van Westen, M. (2018). Ecological-enactive cognition as engaging with a field of relevant affordances: The skilled intentionality framework (SIF). In Oxford handbook for embodied cognitive science, edited by Albert Newen, Leon de Bruin, and Shaun Gallagher. Oxford: Oxford University Press.

Romano, C. (2015). At the heart of reason. Edited by Anthony J. Steinbock. Translated by Michael B. Smith. Evanston: Northwestern University Press.

Schutz, A. (1962). Collected papers I. The problem of social reality. Edited by H. L. van Breda and M. A. Natanson. Phaenomenologica. The Hague: Martinus Nijhoff.

Shapiro, L. A. (2014). Review of radicalizing enactivism: Basic minds without content, by Daniel D. Hutto and Erik Myin. Mind, 123(489), 213-220. https://doi.org/10.1093/mind/fzu033.

Silverman, H. J. (1997). Inscriptions: After phenomenology and structuralism. Studies in Phenomenology and Existential Philosophy. Evanston: Northwestern University Press.

Stawarska, B. (2015). Saussure's philosophy of language as phenomenology: Undoing the doctrine of the course in general linguistics. Oxford University Press.

Taylor, C. (2016). The language animal: The full shape of the human linguistic capacity. Cambridge, Mass: Belknap Press.

Thompson, E. (2007). Mind in life: Biology, phenomenology, and the sciences of mind. Cambridge, Mass: Harvard University Press.

Tomasello, M. (2003). Constructing a language: A usage-based theory of language acquisition. Cambridge, Mass: Harvard University Press.

Walton, R. J. (1991). "Nature and the "primal horizon." In The turning points of the new phenomenological era: Husserl research - drawing upon the full extent of his development book 1 phenomenology in the world fifty years after the death of Edmund Husserl, edited by Anna-Teresa Tymieniecka, 97-112. Analecta Husserliana. Dordrecht: Springer Netherlands. https://doi.org/10.1007/978-94-011-3464-4_6.

Walton, R. J. (1997). World-experience, world-representation, and the world as an idea. Husserl Studies, 14, $1-20$.

Walton, R. J. (2003). On the manifold senses of Horizonedness. The theories of E. Husserl and A. Gurwitsch. Husserl Studies, 19(1), 1-24. 
Welton, D. (1983). The origins of meaning: A critical study of the thresholds of Husserlian phenomenology. The Hague: Martinus Nijhoff.

Welton, D. (2000). The other Husserl: The horizons of transcendental phenomenology. Bloomington: Indiana University Press.

Publisher's note Springer Nature remains neutral with regard to jurisdictional claims in published maps and institutional affiliations. 